\title{
Three-Dimensional Finite Element Simulation of Residual Stress Field For Shot-Peening and Grinding
}

\author{
Jiajin Sun ${ }^{1,}$, Yidu Zhang ${ }^{2, b}$ \\ ${ }^{1}$ School of Mechanical Engineering and Automation, BeiHang University, 100191, Beijing. \\ ${ }^{2}$ School of Mechanical Engineering and Automation, BeiHang University, 100191, Beijing. \\ a446079765@qq.com bydzhang@buaa.cn
}

\begin{abstract}
Keywords: shot-peening; grinding; finite element method; residual stress
Abstract. The modeling and simulation of shot-peening and grinding process was carried out based on ABAQUS, in which the explicit dynamic finite element method was employed. This investigation studies the effect of grinding process on the workpiece residual stress field after shot peening. Furthermore, three-dimensional finite element model of multiple shot peening and grinding was built. The influence of different depth of grinding on the workpiece residual stress field after shot peening was analyzed. Meanwhile, finite element analysis results show that distribution of residual stress almost will not change after shot peening and grinding. But the overall residual stress moves down. Meanwhile grinding can increase residual compressive stress of surface and reduce the residual compressive and tensile stress of subsurface.
\end{abstract}

\section{Introduction}

Shot peening is a process that the a number of high speed projectiles impact the workpiece surface, which can produce a residual compressive stress field on surface to effectively prevent the fatigue crack initiation and propagation, and improve the fatigue life of the workpiece ${ }^{[1]}$. The shot peening has the characteristics of convenient, effective, adaptive, and low consumption. It is very important to study the distribution of residual stress field of shot peening, and to understand the effect of shot peening parameters on the strengthening effect. For the analysis of shot peening, there have been many studies at home and abroad. Baragetti ${ }^{[2]}$ used three-dimensional model to simulate the shot peening process, but it was limited to one projectile. Zhang ${ }^{[3]}$ et al established the three-dimensional model of shot peening, and studied the general rule of the influence of different parameters on the residual stress field.

Grinding is a complex material removal operation, which is performed by the cutting edge of thousands of abrasive grains. Meanwhile, grinding in nature belongs to the category of cutting, but it has its outstanding characteristics, that is, the former angle of grinding grain is negative rake angle $\mathrm{e}^{[4]}$. Due to the large number of abrasive grains, irregular geometry and high grinding speed, the experimental observation and analysis of grinding process is very difficult. Many scholars have carried out the finite element simulation of grinding. Deng ${ }^{[5]}$ et al studied the general rule of the influence of different parameters of grinding on the residual stress field.

Although shot peening can produce a residual compressive stress field on surface to improve the fatigue life of the workpiece, it may increase the roughness of the workpiece surface and affects the lubrication effect. Therefore, in order to increase the fatigue life of the workpiece and ensure the lubrication effect, the simulation of shot peening and grinding is carried out to improve the surface roughness. However, there is no relevant research on the three-dimensional finite element simulation of shot-peening and grinding at home and abroad.

In this paper, ABAQUS is used to establish a three-dimensional finite element model of shot-peening and grinding under the assumption that the initial residual stress of the workpiece is 0 . The influence of different depth of grinding on the workpiece residual stress field after shot peening was analyzed. Moreover, the finite element simulation provides a theoretical reference for the actual shot peening and grinding. 


\section{Finite element model of shot-peening and grinding}

\section{The establishment of geometric model}

In the three-dimensional geometric model, the workpiece is a cuboid and the 42CrMo steel is chosen as its material. It is meshed by hexahedral elements. The projectile is made of steel (rigid body) whose diameter is $0.25 \mathrm{~mm}$. Shot peening is a process that many individual projectiles impact the target, and it is the accumulation of the impact of many projectiles. According to a study, the impact coverage of 9 projectiles on the center of the workpiece is high, and the residual stress field distribution is uniform. So this article selects 9 projectiles model, which is shown in Figure 1

Grinding is a complex material removal operation, which is performed by the cutting edge of thousands of abrasive grains.Single abrasive grain can be seen as a cutting tool with a large negative rake angle. So the model of abrasive grain is simplified to triangular prism whose rake angle is $-60^{\circ}$ and width is $0.3 \mathrm{~mm}$. The elastic modulus and hardness of the abrasive grains are much greater than workpiece. In order to simplify the analysis of the problem, the abrasive grain is regarded as the rigid body. The distribution of abrasive grains is irregular, so this article selects 7 abrasive grains model and they cut the workpiece in turn, which is shown in Figure 2

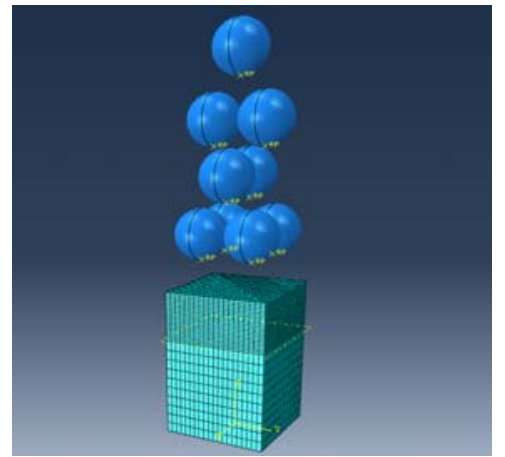

Figure 1: Shot peening finite element model

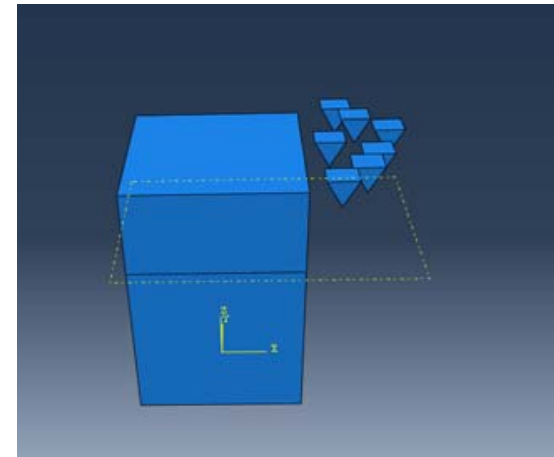

Figure 2: Grinding finite element model

\section{The constitutive model of material}

The grinding process is a complicated process with high temperature, high strain and high strain rate. In order to consider the influence of the factors on the flow stress of the workpiece, Johnson-Cook ${ }^{[6]}$ model is chosen as the constitutive model of the material, which is applied to describe the dynamic behavior of metallic materials from low strain rate to high strain rate. constitutive model parameters of the material is shown in Table 1.The concrete form of Johnson-Cook model is

$$
\bar{\sigma}=\left[A+B\left(\bar{\varepsilon}^{-p l}\right)^{n}\right]\left[1+C \ln \frac{\dot{\bar{\varepsilon}}}{\dot{\bar{\varepsilon}}_{0}}\right]\left[1-\frac{\theta-\theta_{t}}{\theta_{m}-\theta_{t}}\right]^{m}
$$

Type: A - quasi-static yield strength; $\dot{\bar{\varepsilon}}_{0}$ - quasi-static strain rate; $\dot{\bar{\varepsilon}}$ - quivalent plastic strain rate; $\bar{\varepsilon}^{p l}$ quivalent plastic strain; B , n - strain hardening parameter; $\mathrm{C}$ - strain sensitive parameter ; $\theta_{m}$ - normal temperature; $\theta_{t}$ - melting point; $\mathrm{m}$ - Thermal softening coefficient.

TABLE 1: PARAMETERS OF CONSTITUTIVE MODEL

\begin{tabular}{|ccccc|}
\hline $\mathrm{A} / \mathrm{MPa}$ & $\mathrm{B} / \mathrm{MPa}$ & $\mathrm{n}$ & $\mathrm{C}$ & $\mathrm{m}$ \\
\hline 595 & 580 & 0.133 & 0.023 & 1.03 \\
\hline
\end{tabular}

\section{Fracture criterion of material}

In the process of finite element analysis, the failure criterion is a very important parameter. Only when the software analysis the critical value of the workpiece material to be removed accurately, the workpiece material can be successfully removed. The failure criterion of material is that when a unit's characteristic parameters such as stress, strain, or other parameters can reach the specified critical 
value, we think that the unit is completely destroyed. Then the unit is removed. The finite element program provides a lot of judgment standard of failure criteria, mainly is the maximum plastic strain, the maximum principal stress, the maximum equivalent stress, the maximum principal strain, stress threshold, the minimum time step, the maximum stress, the stress pulse, etc. We often use J-C shear failure criterion, which is applied to the deformation of metal in high temperature and high strain rate. When the equivalent plastic strain of the element material in the shear zone reach 1, the unit is separated from the workpiece and form the chip. Failure criterion parameter of the material is shown in Table 2 and equivalent plastic strain is

$$
\bar{\varepsilon}_{D}^{p l}=\left[d_{1}+d_{2} \exp \left(d_{3} \frac{p}{q}\right)\right]\left[1+d_{4}\left(\frac{\dot{\bar{\varepsilon}}_{0}}{\dot{\dot{\varepsilon}}}\right)\right]\left[1+d_{5} \hat{\theta}\right]
$$

Type: $d_{1} \sim d_{5}$-failure coefficient; $\dot{\bar{\varepsilon}}_{0}$ - plastic strain rate; $\dot{\varepsilon}_{0}$ - reference strain rate; p compressive stress; q - Mises stress.

TABLE 2: FAILURE PARAMETER OF ELEMENT

\begin{tabular}{|ccccc|}
\hline $\mathrm{D}_{1}$ & $\mathrm{D}_{2}$ & $\mathrm{D}_{3}$ & $\mathrm{D}_{4}$ & $\mathrm{D}_{5}$ \\
\hline 0.088 & 4.7 & 3.15 & 0.002 & 0.61 \\
\hline
\end{tabular}

\section{Simulation results and analysis}

In the process of shot peening, assuming the initial residual stress of the workpiece is 0 and 9 projectiles at a speed of $100 \mathrm{~m} / \mathrm{s}$ hit the workpiece in turn. The coverage on the center of the workpiece is the highest, and the residual stress field distribution is the most uniform, which is shown in Figure 3. The transverse residual stress parallel to the surface of the workpiece plays a major role in blocking the surface fatigue crack generation and expansion of the workpiece. So the residual stress of this paper refers to the transverse residual stress.

In order to accurately display the residual stress results in the $\mathrm{X}$ direction, residual stress is shown in the form of path. In the middle of the workpiece, I select 35 nodes to build a path from the machined surface to the bottom. Then the rule of the variation of the residual stress with the surface depth is obtained. As shown in Figure 4, the residual stress of workpiece surface is compressive stress, and the farther the distance from the surface, the larger the compressive stress. The maximum value of the compressive stress is $1100 \mathrm{Mpa}$.Then the compressive stress gradually change to tensile stress, and finally converge to zero.

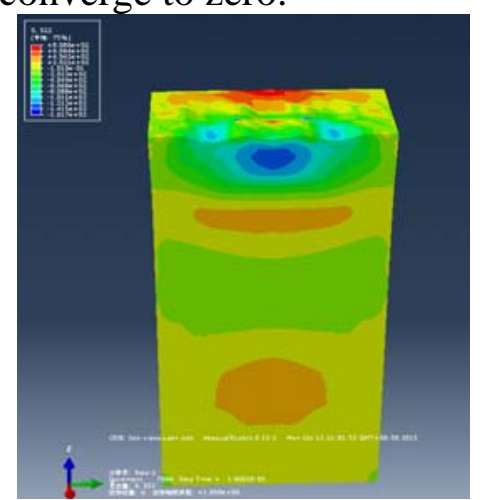

Figure 3: Finite element simulation results of shot peening

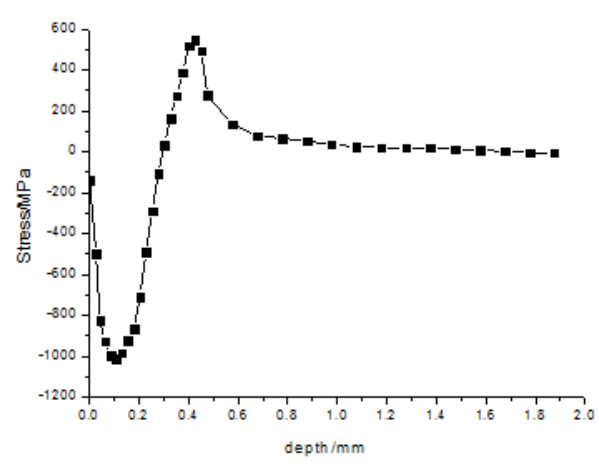

Figure 4: $\mathrm{x}$ stress distribution of shot peening

In the process of grinding, put 7 identical abrasive grains on the right side of the workpiece irregularly. Each abrasive grain is a triangular prism and its rake angle is $-60^{\circ} .7$ identical abrasive grains at a speed of $50 \mathrm{~m} / \mathrm{s}$ grind workpiece being impacted by shot peening. It is grinded four times and each time grinded $0.02 \mathrm{~mm}$. The simulation process is shot-peening then grinding, in order to simplify the calculation process, the residual stress field is applied on the workpiece to be used for grinding. The residual stress field of grinding is shown in Figure 5. The 4 times' residual stress 
distribution in the middle section of the workpiece is obtained by using the method of path and the starting point of the stress is the surface of the workpiece after grinding. As shown in Figure 6.

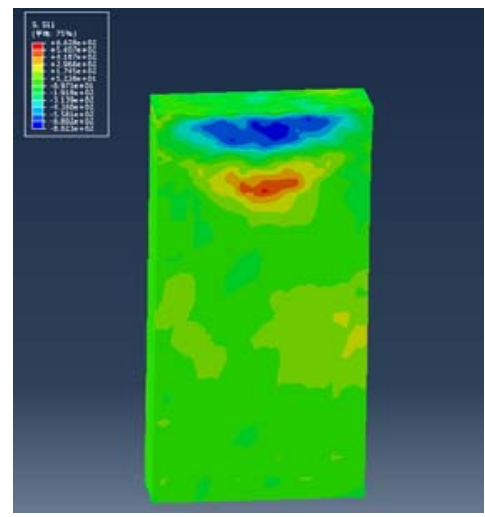

Figure 5: Finite element simulation results of grinding

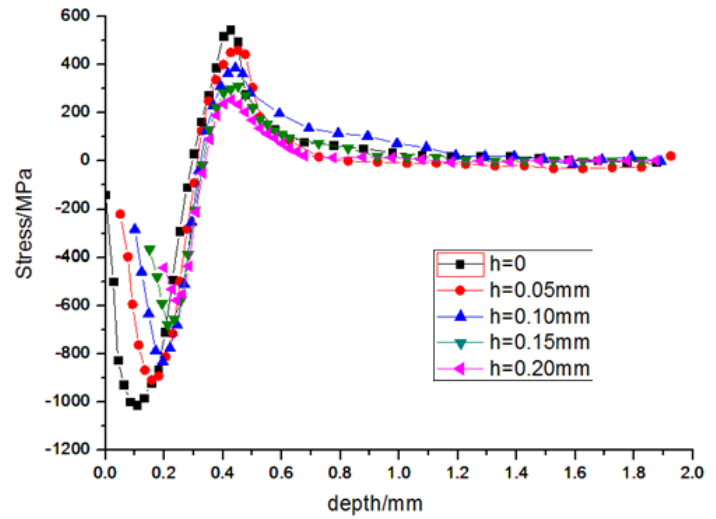

Figure 6: $\mathrm{x}$ stress distribution of different grinding depth

After 4 times' grinding, the distribution of the residual stress in the workpiece is basically the same as that of the residual stress before grinding process. The residual stress on the surface of the workpiece is compressive stress and with increasing the depth of the workpiece, the greater the compressive stress. Then the compressive stress gradually change to tensile stress, and finally converge to zero. However, the overall residual stress moves down, and the moving distance and the depth of grinding are basically consistent. With the increase of the grinding depth, the residual compressive stress on the surface of the workpiece increases gradually from $130 \mathrm{MPa}$ to $450 \mathrm{MPa}$. But the maximum residual compressive stress in the subsurface layer decreases gradually from $1050 \mathrm{MPa}$ to $630 \mathrm{MPa}$. At the same time, the maximum tensile stress also gradually decreases. Therefore, we know that the distribution of residual stress almost will not change after shot peening and grinding. But grinding can increase residual compressive stress of surface and reduce the residual compressive and tensile stress of subsurface.

\section{Conclusion}

1) In this paper, the finite element model of shot peening is established by using the finite element software ABAQUS. The uniform residual stress field in the middle section of the workpiece is obtained by the impact of 9 projectiles. The distribution of the residual stress field of shot peening is analyzed, which is the basis of the analysis of the influence of grinding on the residual stress field.

2) Finite element analysis results of grinding show that the distribution of residual stress almost will not change after shot peening and grinding. But the overall residual stress moves down, and the moving distance and the depth of grinding are basically consistent. Meanwhile grinding can increase residual compressive stress of surface and reduce the residual compressive and tensile stress of subsurface.

\section{References}

[1] Weiling luan, Shandong Tu "The research progress of shot peening surface modification technology”, Journal of Mechanical Engineering, 2005,16(15):1405-1409. "In Chinese”

[2] Baragetti S.Three-dimension finite element procedures for shot-peening residual stress field prediction[J].International Journal of Computer Applications in Technology,2001,14:51-63.

[3] Hongwei Zhang, Yidu Zhang. "Three-dimensional numerical analysis of residual stress field for shot-peening “, Journal of Aerospace Power,2010,25(3);603-609. "In Chinese”

[4] Bomin Li, “Grinding principle”[M],Beijing:Machinery Industry Press,2003. “In Chinese” 
[5] Chaohui Deng,"Finite-element Simulation and Experiment on the Residual Stress When Grinding Nanostructured WC/12Co Coatings”, Journal of Mechanical Engineering, 2008, (7): 58-62. “In Chinese"

[6] BargeM,HamdiH, Rech J, et al Numerical modelling of orthogonal cutting influence of numerical parameters [J]. Journal of Materials Processing Technology,2005(164 -165). 